\title{
Enciclopédia polifônica: a construção dos textos e das vozes em Art Book
}

\author{
Polyphonic encyclopedia: the construction of texts and voices in Art Book
}

\author{
BRUNO MORESCHI * \\ Universidade Estadual de Campinas, SP, Brasil
}

\begin{abstract}
Resumo: O artigo discute o conteúdo textual e as vozes presentes em Art Book, uma enciclopédia de artistas e obras criada a partir da identificação dos clichês encontrados em outras publicações do gênero e tema do mestrado em Artes Visuais na Unicamp do pesquisador e artista Bruno Moreschi. As vozes narrativas presentes em Art Book são diversas, e o texto aqui discute algumas de suas características e como elas atuam conjuntamente na criação de um efeito de pluralidade e veracidade presente no livro, que pode ou não se percebido como ficcional pelo leitor.
\end{abstract}

Palavras-chave: arte contemporânea; enciclopédias de artistas; biografias; autoria.

\begin{abstract}
The article discusses the textual content of Art Book, an encyclopedia of artists and works created from the identification of the cliches and patterns identified in other publications of the genre and theme of Bruno Moreschi's thesis in Visual Arts at Unicamp. The signatures present in Art Book are diverse, and the text here discusses some of its characteristics and how they act in creating an effect of plurality and veracity present in the book, which may or may not be perceived as fictional by the reader.
\end{abstract}

Keywords: contemporary art; encyclopedias of artists; biographies; authorship.

\footnotetext{
* Pesquisador acadêmico e artista visual. Doutorando em Artes Visuais pela Universidade Estadual de Campinas (Unicamp), com bolsa da Coordenação de Aperfeiçoamento de Pessoal de Nível Superior (Capes), e passagem na University of Arts of Helsinki (Kuva Art Academy), Finlândia. É mestre em Artes Visuais pela Universidade Estadual de Campinas (Unicamp), tendo sido pesquisador bolsista da Fundação de Amparo à Pesquisa do Estado de São Paulo (Fapesp), e passagem pela Universidade de Coimbra, Portugal. Suas investigações acadêmicas estão relacionados ao sistema das artes visuais, à arte conceitual e aos espaços de legitimação de arte. Atualmente, estuda experiências não tradicionais de visitações em museus históricos e nacionais.
} 


\section{Introdução}

Tudo tenta parecer convincente em Art Book. A capa (Fig. 1) apresenta uma fotografia com manchas amarelas, verdes e azuis, detalhes de um vídeo da artista Marie Parker exibido em 2013 nos telões da Times Square, Nova York. Próximo das letras em maiúsculas $A R T B O O K$, somos informados de que o livro é editado por Bruno Moreschi e equipe, uma das vozes que será discutida neste artigo. $\mathrm{O}$ intertítulo lança a principal promessa do projeto editorial: comprimir a arte de hoje em 50 artistas contemporâneos / 50 artistas contemporáneos / 50 contemporary artists - assim, trilíngue, como são todos os textos da publicação.

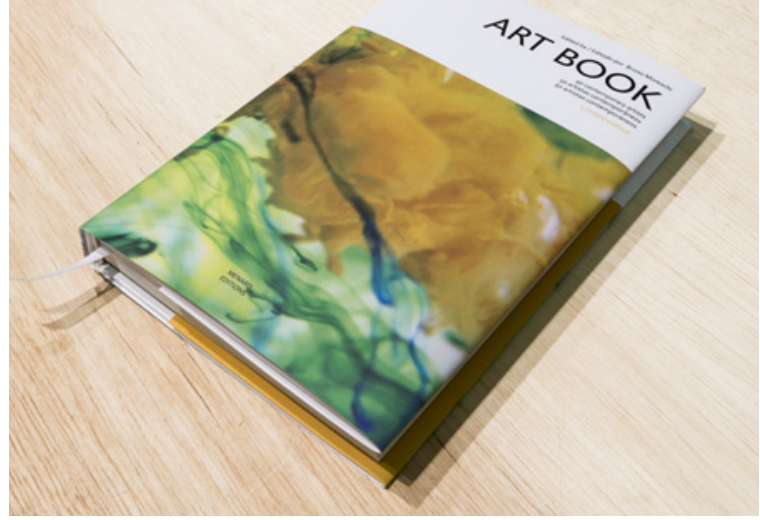

Figura 1. Capa da enciclopédia Art Book.

A estrutura de Art Book é tal qual as encontradas em conhecidas enciclopédias de artistas contemporâneos e inclui um breve prefácio assinado pelo editor, biografias, fotografias de trabalhos, currículos, além de declarações de artistas que, na sua maioria, são homens brancos europeus ou estadunidenses. As fotografias das 311 obras de arte apresentadas na enciclopédia abrangem técnicas artísticas diversas. Entre elas, pintura (a maioria a óleo, mas também acrílica e aquarela), desenho, escultura, fotografia, vídeo, performance, instalação, arte digital e também ações de difícil categorização, mas nem por isso desprezadas no campo da arte, como guardanapos sujos coletados em padarias de grandes cidades do mundo - obra conferida ao brasileiro José dos Reis.

O cardápio é extenso, mas com opções familiares. Um polêmico artista inglês apresentado no livro afirma que nada é pior do que o conformismo, mesmo que seu currículo faça com que ele se encaixe perfeitamente na definição de ARGAN (1992, p. 208) para grandes artistas: “... inspirados e rebeldes, mas geralmente prontos a fazer todas as concessões." Há também o autor de instalações com hologramas de corpos humanos que questionam a fronteira entre real e virtual, o estadunidense crítico à sociedade de consumo, a iraniana preocupada com a liberdade das mulheres no Oriente Médio, o criador conceitual também professor universitário, o sul africano que vive e trabalha na Europa, a pintora brasileira conhecida por suas telas de cores chamativas, dentre outros 43 nomes.

Em 2014, com o apoio da Fapesp e dos prêmios Funarte de Arte Contemporânea e Bolsa Funarte de Estímulo à Produção em Artes Visuais, Art Book foi impresso com tiragem de 200 exemplares e, junto a uma dissertação, apresentado em banca examinadora do Instituto de Artes da Unicamp como pesquisa de mestrado em artes visuais do artista visual Bruno Moreschi. O projeto discutiu questões relacionadas à autoria e à legitimação nas artes visuais inseridas no processo de se criar 
uma enciclopédia como essa, construída a partir de clichês e padrões identificados em outras publicações do tipo - a saber, as enciclopédias Art Now volumes 1, 2 e 3; 100 Contemporary Artists; Creamier; Rising - Young Artist to keep an eye on! e a coleção Vitamin.

Desde então, o livro tomou seu caminho. Alguns exemplares podem ser encontrados em bibliotecas de museus no Brasil, Espanha, Finlândia e Alemanha. Outros, na casa de pessoas exibidos como um legítimo coffee book table. Em seis momentos até agora, o livro foi exibido em espaços expositivos (Fig. 2) - um deles com o direito a uma ação complementar que beirou um teatro do absurdo: um seminário sobre a publicação e uma outra semelhante criada pela artista espanhola Cristina Garrido. Na ocasião (Fig. 3), não só Garrido e Bruno Moreschi editor estiveram presentes, mas também as curadoras Veronica Stigger e Marta Ramos-Yzquierdo. O grupo foi mediado pelo jornalista especializado em artes visuais (pelo menos assim descrito no seminário) Renan Rovida que, no meio do evento e para espanto de quase todos, irritou-se com o toque de um celular, levantou-se e foi embora do palco. As surpresas não terminaram nesse ponto. Seis atores também foram colocados na plateia para fazerem perguntas nonsenses aos convidados o que estimulou o público restante a fazer o mesmo.



Figura 2. Art Book: At your own risk, exposição no Espaço Cultural Marcantonio Vilaça, Brasília, Brasil, 2017.

Figura 3. This is Art Now \& ART BOOK: If it's hot in the art world is in these books, this seminar and this Triennial (2014). Seminário com Bruno Moreschi, Cristina Garrido, Veronica Stigger, Marta Ramos-Yzquierdo, Renan Rovida. Projeto realizado para Frestas - Trienal de Artes/SESC Sorocaba, Brasil, curadoria Josué Mattos.

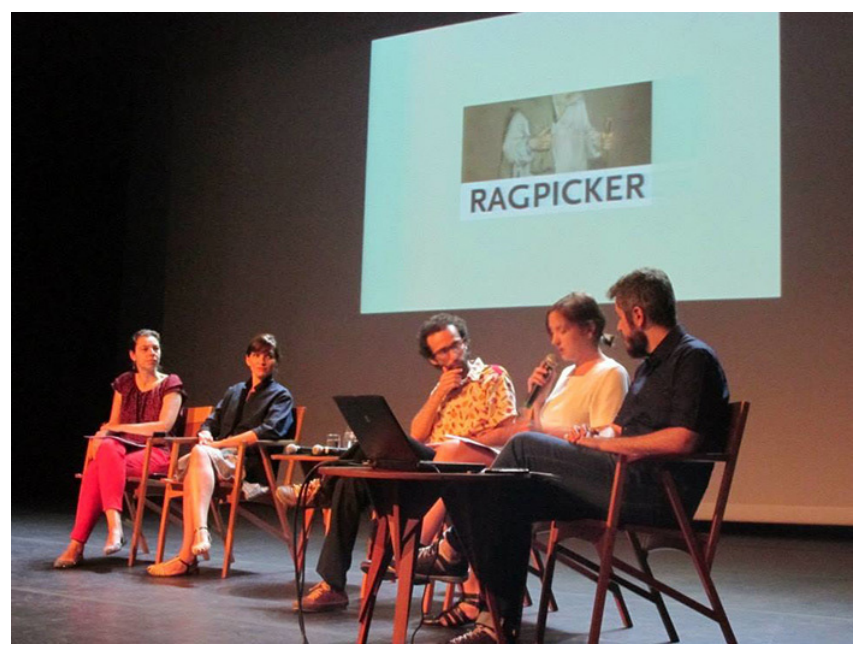


Apesar de certa regularidade na exibição de Art Book, inclusive com seu editor testando-o em outros formatos que não só o da leitura como foram as exposições e o seminário-teatro, nesses últimos três anos poucas vezes o livro foi discutido a partir de seu conteúdo textual. As discussões e as exibições públicas do projeto tiveram como foco aquilo que ele discute ser recorrente na arte contemporânea: os clichês, os cacoetes, os padrões, chame do que quiser os signos visuais exibidos em renomados museus, galerias, publicações e que são replicados em Art Book. Em outras palavras, discutiu-se mais o que se vê (a partir de um tipo específico de fotografia) do o que ali se lê.

Sobre o uso das imagens em Art Book, chamo atenção para a importância da fotografia da obra de arte na legitimação de trabalhos artísticos, operação fundamental para que tudo que reluz nesses livros de arte pareça ouro. Entender os procedimentos da documentação fotográfica da obra de arte parece ter sido condição fundamental de Bruno Moreschi editor para tornar o livro o mais coerente e convincente possível. A questão é das mais estruturantes do campo das artes visuais: nos livros, a História da Arte não é a história dos objetos e das experiências artísticas, é a história de suas fotografias.

Isso, porém, é assunto para outro artigo. Interessa-me aqui discutir os textos de Art Book, suas assinaturas e como eles ajudam a construir o sistema dessa enciclopédia de artistas contemporâneos. Para isso, é preciso identificar essas vozes, compreendendo o efeito de pluralidade e de veracidade que elas ajudam a construir na publicação. $\mathrm{O}$ artigo parte do pressuposto que o livro aqui discutido tenta a todo momento ser uma espécie de enciclopédia polifônica, termo utilizado pelo filósofo russo Mikhail Bakhtin para caracterizar alguns textos marcados por vozes controversas em seu próprio sistema discursivo.

\section{O editor Bruno Moreschi e equipe}

O editor de Art Book assina o primeiro texto do livro como "Bruno Moreschi e equipe", assinatura que sugere certa diversidade autoral, mas que é falácia, já que ele jamais nomeia de fato quem o acompanha no projeto editorial. No texto, que é o prefácio da publicação, Bruno Moreschi editor tenta transformar algumas possíveis críticas ao projeto que poderão vir dos leitores em erros que não são dele "e equipe", mas inerentes do empreendimento proposto - o de apresentar um panorama da arte contemporânea.

Isso faz com que o prefácio seja uma ação defensiva de quem sabe que produziu algo com lacunas facilmente perceptíveis. Duas delas são evidentes antes menos de uma análise minuciosa ao livro, saltam aos olhos já na contracapa, que lista os artistas discutidos na publicação. Falo da falta de explicação a respeito da metodologia aplicada na escolha desses nomes a serem analisados no livro, e dúvidas quanto à veracidade acerca deles, já que informações desses artistas não são encontrados em nenhuma outra fonte que não Art Book.

É bem verdade que a primeira lacuna, a questão metodológica, é um ponto fraco de praticamente todas as enciclopédias de arte contemporânea no estilo de Art Book. Nelas, a voz do editor costuma ser a da autoridade que vende ao leitor a promessa de uma seleção primorosa de artistas - em número redondo de 50 em Art Book, mas que também surge como os 10 , os 25 , os 100, os 1000 artistas/músicas/livros/lugares/ 
vinhos etc. que você precisa conhecer antes de morrer. Em comum nessas listas está o fato dos critérios metodológicos das escolhas nunca serem apresentados ao leitor, afinal, esses critérios, se existirem, são de uma curadoria pautada pelo mercado de arte e consumo, e não de "Bruno Moreschi e sua equipe" ou algum outro time de especialistas independentes.

No prefácio, Moreschi editor não explica como chegou aos 50 notáveis e questões importantes permanecem em aberto. Quantos artistas foram pesquisados para se chegar a esse número? Como foram as reuniões com sua equipe? Houve uma preocupação em incluir um número mínimo de artistas fora dos Estados Unidos e Europa, além de mulheres (negras ou não) e negros? No prefácio, nenhum esclarecimento sobre esses questionamentos. O que há no texto é uma rede de argumentos que constroem uma defesa a priori que identifica problemas inerentes ao próprio ato de se selecionar, uma ação que, segundo o prefácio, envolve exclusões e injustiças além da responsabilidade de Moreschi editor:

Concordamos com o escritor argentino Jorge Luis Borges: 'Selecionar é guiar o rumo da História.' Por si só, a afirmação carrega a responsabilidade inerente à seleção. Borges complementa: 'Poucos são os espaços vagos. Muitos são aqueles que almejam ocupá-los.' Parece, portanto, que a própria ação de selecionar produz invariavelmente injustiças e equívocos. Isso se potencializa ainda mais quando a seleção restringe-se a uma quantidade irrisória de selecionados (...) Desde o início, estávamos cientes: éramos um grupo fadado ao erro (MORESCHI, 2014, p. 5).

Mas o que é confissão de culpa no primeiro parágrafo ("éramos um grupo fadado ao erro"), torna-se no segundo uma equívoco menos grave, pois produz uma espécie de consequência positiva inevitável. Para explicar melhor essa compensação, Moreschi editor cita não mais Borges, mas Michel Foucault e Heráclito de Éfeso estranhamente sem as devidas referências bibliográficas:

A sorte é que um dos apontamentos do francês Michel Foucault relativiza minimamente o fardo da ação seletiva: 'A seleção não diz respeito aos escolhidos. Estes não são apenas os eleitos, mas também representantes máximos de ações que englobam um número maior de pessoas que agem como eles. Dentre os escolhidos há também os desclassificados - eis a razão dos eleitos carregarem consigo o mérito de serem sínteses de outros.' Assim como 'o morto não é um morto: é a morte', o artista é, além de seu nome, também a arte. Trata-se de um consolo. Podemos aqui justificar nossas falhas afirmando que pouco importa a escolha pelos eleitos ou não eleitos. Qualquer das vias trataria do mesmo universo. 'Entrai, que aqui também estão os deuses', disse Heráclito de Éfeso às pessoas que o encontraram aquecendo-se na cozinha (MORESCHI, 2014, p. 5).

Moreschi editor também se protege de futuras críticas a partir do argumento de que seus equívocos são não só resultado do ato da seleção, mas também do próprio campo da História da Arte: "Somos conscientes de que, a despeito de qualquer metodologia aplicada, a História da Arte, como qualquer outra narrativa, é feita de contradições, lacunas e construções nunca totalmente sedimentadas" (MORESCHI, 2014, p. 5).

Assim é a defesa para a deficiência metodológica de Art Book: colocar a culpa em sistemas maiores do que o próprio 
editor e sua equipe, que se apresentam apenas como um time sem saída e que necessariamente precisam replicar os erros (e os acertos) do ato de se selecionar e do ato de se analisar algo sob o ponto de vista histórico. Jogando a culpa em outros, Moreschi editor não só se protege das críticas, como também tenta se beneficiar do fato de ser o primeiro a evidenciá-las, tornando-se voz consciente, franca e também merecedora de certa simpatia do leitor menos atento.

Sobre as dúvidas acerca da veracidade das informações contidas no livro, o editor segue a linha de um discurso de confissão de culpa minimizada pelos benefícios inerentes do sistema que atua. A diferença é que, para essa lacuna, ele é bem mais conciso do que em relação aos problemas metodológicos da seleção de artistas. Sobre a credibilidade do livro que poderá vir a ser colocada em jogo pelo leitor, o editor reserva apenas as três últimas frases do prefácio: "O todo certamente não está aqui. Mas o todo também nunca está pronto. Não pode haver senão rascunhos. Melhor ainda se eles forem convincentes" (MORESCHI, 2014, p.5).

Em nenhum outro momento, o editor aparece de forma explícita (ou seja, com sua assinatura) em Art Book. Também pudera: a despeito de qualquer outra crítica proveniente do livro, ele pode sempre recorrer ao argumento de que não poderia ser diferente, pois está inserido em um projeto que o obriga a cometer equívocos. Protegido já no prefácio da obra e com argumentos que assumem não os erros exclusivos do projeto, mas os efeitos colaterais da estrutura enciclopédia de arte contemporânea, Moreschi editor é a voz mais bem resguardada do livro.

\section{Os biógrafos}

Marcada fortemente por um tom publicitário, Art Book tem estrutura semelhante à encontrada em uma outra enciclopédia, a conhecida Art Now, já no seu quarto volume. O livro é vendido no site de sua editora, a alemã Taschen, como "um tomo tal qual um tour global nas galerias mais influentes do mundo" e seu slogan é direto: "se é imperdível no mundo das artes de hoje, está nesse livro." Art Book não deixa por menos e, na contracapa, afirma abranger os 50 artistas mais essenciais do mundo com seus 311 incríveis trabalhos de arte.

Mas não só a linguagem direta de Art Now influenciou Art Book. Tal lá quanto cá, as biografias dos artistas (Fig. 4) são assinadas por nomes ditos pelas duas publicações como especialistas em artes visuais - a saber, críticos de arte, curadores, escritores e jornalistas dos mais diferentes locais do mundo. Em Art Now volume 3, Adriano Pedrosa, curador chefe do Museu de Arte de São Paulo (Masp), e Rodrigo Moura, curador de Inhotim, Brumadinho, são os únicos brasileiros dentre os biógrafos.

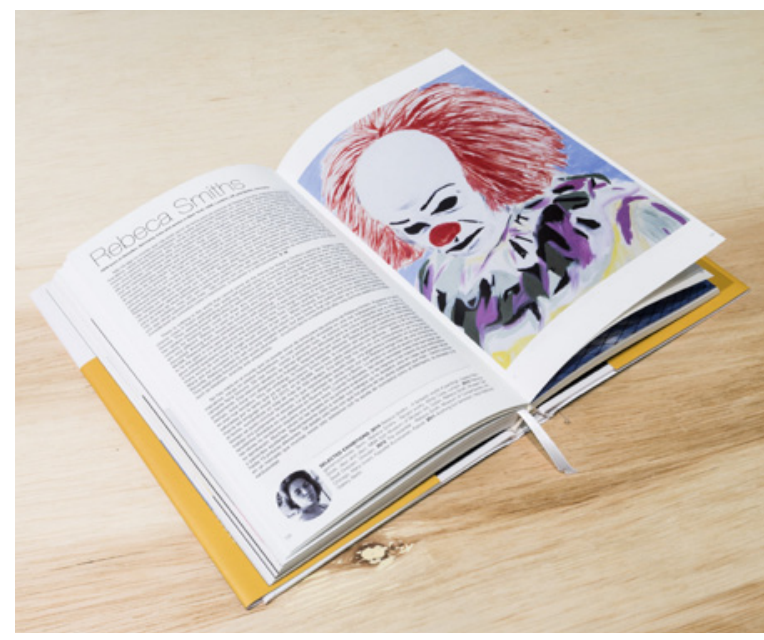

Figura 4. Uma das páginas dos artistas de Art Book. 
O mesmo não se vê em Art Book, no qual não há nenhum especialista em artes do Brasil, apesar da presença de dois artistas brasileiros dentre os 50 eleitos (a pintora Paula Sampaio e o já citado José dos Reis). É na penúltima página do livro que os autores das biografias são apresentados:

Andrew Lange (A. L): realizou seus estudos em arte contemporânea no Royal College of Art de Londres e já organizou mais de 50 exposições pela Europa.

Elen Curry (E. C.): editora do catálogo anual Artist of the year, uma importante seleção dos mais importantes artistas e suas exposições do ano vigente.

Ed Depnneu (E. D): historiador de Arte e professor do Centro de Estudos de Arte Contemporânea (CEAC) de Nova York.

Gllen Powel (G.P.): editor e crítico de arte. Responsável pela modernização do acervo de arte contemporânea dos museus municipais e estaduais de Bogotá. Também é consultor de arte.

John Hunt (J.H.): escritor e crítico independente, já realizou mais de 1.000 entrevistas com artistas de todo o mundo.

Rosaly Meese (R.M.): editora chefe da revista $\mathrm{OH}$ ART!, a jornalista especializada em artes visuais realizou, em 2000, na Tate Modern, a curadoria da prestigiada exposição 2000 Artists.

Rachel Gordon (R.G.): consultora e crítica independente, mora atualmente em Berlim. Escreve regularmente para revistas de arte de todo o mundo.

Robert Epson (R.E.): colabora para diversas revistas de arte nos Estados Unidos, entre elas, ArtToday, EA Editions of Art e Frook.

Paulo Caivano (P. C.) diretor responsável pelas Bolsas Ford de Estudos Artísticos, que já financiou artistas de mais de 20 países (MORESCHI, p. 245).
Nesses currículos resumidos, os nomes e sobrenomes dos especialistas são seguidos de suas iniciais, pois é dessa maneira diminutiva que suas assinaturas aparecem nos finais das biografias dos artistas de Art Book. Reduzir essas vozes a siglas e apresentar os nomes completos dos autores somente no término do livro, próximos dos créditos fotográficos das imagens e do expediente, área geralmente ignorada pelo leitor, comprova o que o aposto "e equipe" sugere na assinatura de Moreschi editor presente no prefácio: é com o efeito de diversidade que o Art Book se preocupa, não com a diversidade de fato.

Para além do modo que se dá essas assinaturas, um rápido estudo dos textos dessas biografias indica algo que reforça essa constatação de falsa pluralidade de vozes. Apesar do livro apresentar 50 biografias escritas por nove especialistas diferentes, esses textos não se diferem entre si. Parecem terem sido escritos por uma mesma pessoa ou, pelo menos, fortemente editados por Bruno Moreschi e equipe.

As nove assinaturas parecem operar a partir de um mesmo aparato ideológico, sistema discursivo esse que é o da própria arte contemporânea. Por isso, melhor analisá-las a partir do que essas vozes defendem como parte do conjunto de práticas legitimadas como arte (em Art Book e nas artes visuais de modo mais geral). Para reforçar essa escolha de avaliação dessas vozes por blocos de ideias defendidos e não pela assinatura do biógrafo, detenhome aqui em quatro desses conceitos, todos formulados por ao menos dois autores diferentes das biografias. São eles: a arte como sistema altamente codificado e, por vezes, inconclusivo; a polêmica como forma de expressão artística; a natureza e o corpo humano como tema; e uma 
certa defesa pela pertinência da pintura no campo ampliado da arte contemporânea.

Sobre a arte como sistema codificado, em algumas das biografias, a discussão dos trabalhos dos artistas parecem chegar não a uma conclusão definitiva sobre o que eles significam de forma específica. São apontamentos que evidenciam margens de indefinições no significado da obra de arte e alto grau de laconismo. É como se a arte, quando bem vista, não fosse capaz de entregar ao público nenhum tipo de certeza e, por isso, pode decepcionar aos mais carentes de definições. Para Rosaly Meese, a recompensa de se apreciar um vídeo de quase três horas de duração do francês Pierre Wallace que mostra em câmera lenta apenas uma jovem saindo do mar não é das maiores: "É como se Wallace estivesse sugerindo que precisamos observar com atenção as coisas ao nosso redor. E, depois disso, concluir que de fato quase nada realmente importa." (MORESCHI, p. 190)

O mesmo parece acontecer na descrição de John Hunt sobre Ideologies mobile in human supports do indiano Falak Shakti, que convida pessoas do centro de Nova Deli a carregarem faixas com suas considerações sobre a vida (Fig. 5). Para Hunt, apesar da ação já ter contado com a participação de mais de 200 indianos e resultado em uma importante exibição individual do artista, o trabalho artístico não consegue sintetizar as vozes das ruas, visto que o primeiro dos cartazes expostos é do próprio Shakti e informa: "Não há consenso algum."

O conceito enigmático, lacônico e em certo grau até mesmo ineficaz (sob o ponto de vista comunicacional) da arte discutido nessas e em algumas outras biografias de artistas de Art Book parecem evidenciar a máxima de que a arte não é feita para explicar, mas para confundir - um eufemismo que mantém o campo da arte contemporânea reservado à elite intelectual de determinada sociedade.

Não parece por acaso que Art Book tenha entre suas anedotas biográficas casos que reforçam a aura da obra de arte. Ao entregar ao leitor familiarizado com arte contemporânea, tipos de artistas e de experiências artísticas já esperadas por esse leitor iniciado, a publicação parece mais preocupada em reforçar o fetichismo da arte do que desanuviar o sistema artístico altamente codificado que é tema do livro. É exatamente o que faz Rosaly Meese, a mesma da biografia de Wallace, ao tratar de uma pilha de latas de conteúdo desconhecido assinada pelo belga Jakov Grün. Ela apenas repassa a história, sem questionar sua validade: "Certa vez, alguém Ihe questionou: 'O que há em suas latas?' Grün respondeu: 'O mistério da arte.'" (MORESCHI, p. 42).

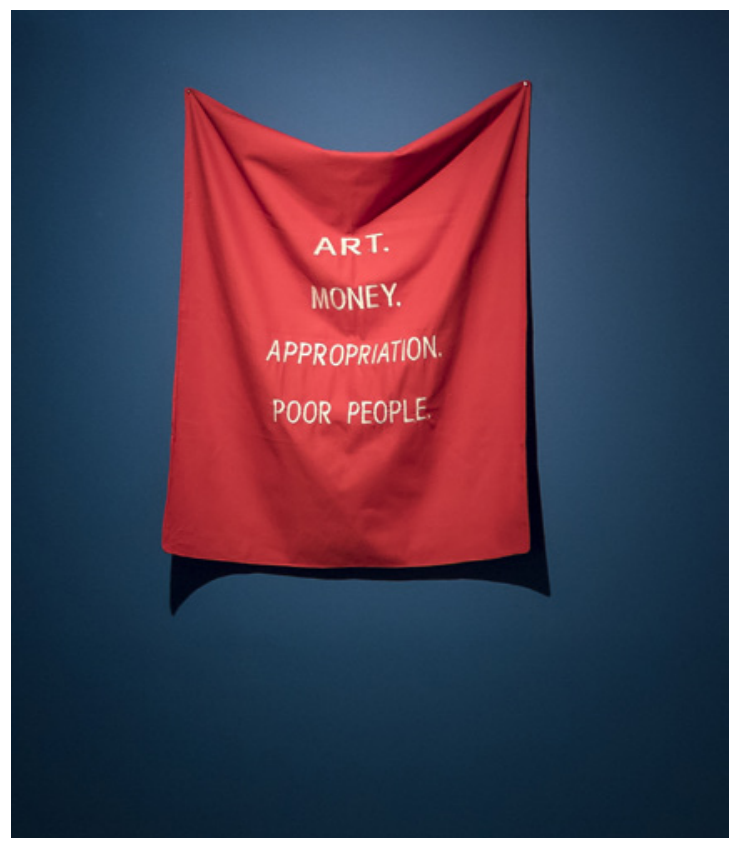

Figura 5. Imagem do trabalho Ideologies mobile in human supports, de Falak Shakti. 
Se Art Book se isenta da responsabilidade de explicar o que diz ser arte, ações subversivas diversas podem ser facilmente legitimadas como artísticas em suas páginas. Parte considerável dos 50 artistas da enciclopédia (ao menos 15), flertam com a polêmica. Andrew Lange conta que as gêmeas Hamona \& Hillary (Fig. 6) já eram figuras controversas no mundo das artes em Berlim antes mesmo de decidirem ser artistas: "Não raras vezes, elas iam às festas vestidas iguais e costumavam trocar de identidades conforme as horas passavam" (MORESCHI, p.42). Ainda de acordo com Lange, são elas as autores de obras tão lacônicas quanto controversas: "H\&H também já fizeram séries de pinturas totalmente brancas; desenhos com avisos de que aquele trabalho foi apenas fruto de um movimento involuntário de suas mãos e um conjunto de esculturas invisíveis que literalmente não era coisa alguma" (MORESCHI, p.42).

Mas se considerarmos a biografia escrita por Ed Depnneu, é certamente a londrina Marie Thompson a mais polêmica do grupo de artistas de Art Book. Uma fotografia de bichinhos fofos em posições

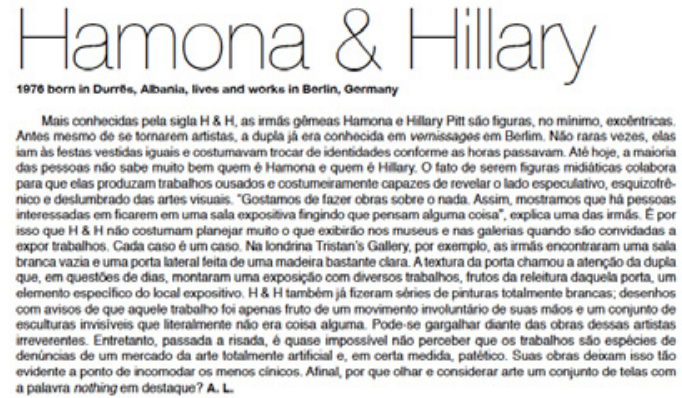

Better known by the intials $\mathrm{H} 8 \mathrm{H}$, the twin sisters Hamona and Hillary Pitt are eccenticic characters, to say the

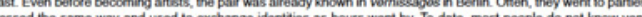
dressed the same way and Lsed to exchange identitios as hours went by. To date, most people do not know very ing and usually able of revealing the speculative, schizophrenic and dazzod side of visual ants. We like no make works about nothing This way, we show that there are pecele intorested in being in an exhibition room pretending To think about something, explans one $d$ the sisters. That is the reason why H\&H do not plan about what they wil

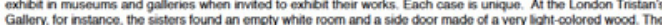
lexture $\alpha$ the door called the attention $d$ the pait, who, whthin days, set up an exhibison with several works, frut of the reinterpretation of that doot, a spectice elemert of the exchibition place. HSH have also made a series of totally

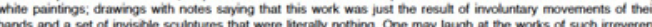
artists. However, atter laughing, it is almost impossible not to realize that the works are a kind of denunciation of lotally articial ant market and, sometow. pathetic. Their works make it so evidert to the pcim of arnoying the less

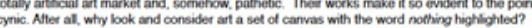

Más conocidas por la sigla HSH, las hermanas gemelas Hamona y Hillary Pitt son figuras, por bo menos, exotem.

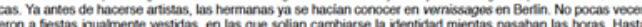
hoy ta maycria de las personas no sabe bien quién es Hamona y auién es Hilarry El thecho de que sean persones lamosas potencializa la producoín de trabajos osados y capaces de revelar ell lado especulativo, esquizotrinico y destumbrado de las artes visuabes. Nos gusta hacer obras de ante sobre la nada Asi, demostramos que hay personas interesadas en estar en una sala fingendo que algo saben, explca una de las hermanas Es por ess y vacia, y una puerta lateral hecha en madera muy clara La lextura de la puerta les llamól la atenoion, y en pooses

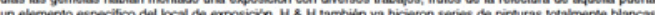
un elemento espocitico del local de exposicon. $\mathrm{H} 8 \mathrm{H}$ tambien ya hicoton series de pinturas totalmente blancas. les artistas. Sin embargo, pasada la risa, es cassi imposible no percobier que sus trabajos son como denuncias de un

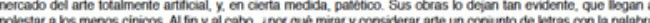
notiting en destaque?

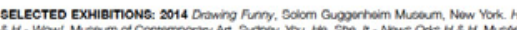

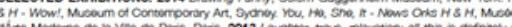

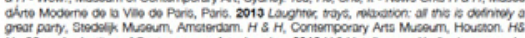

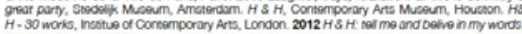

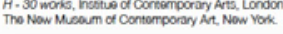
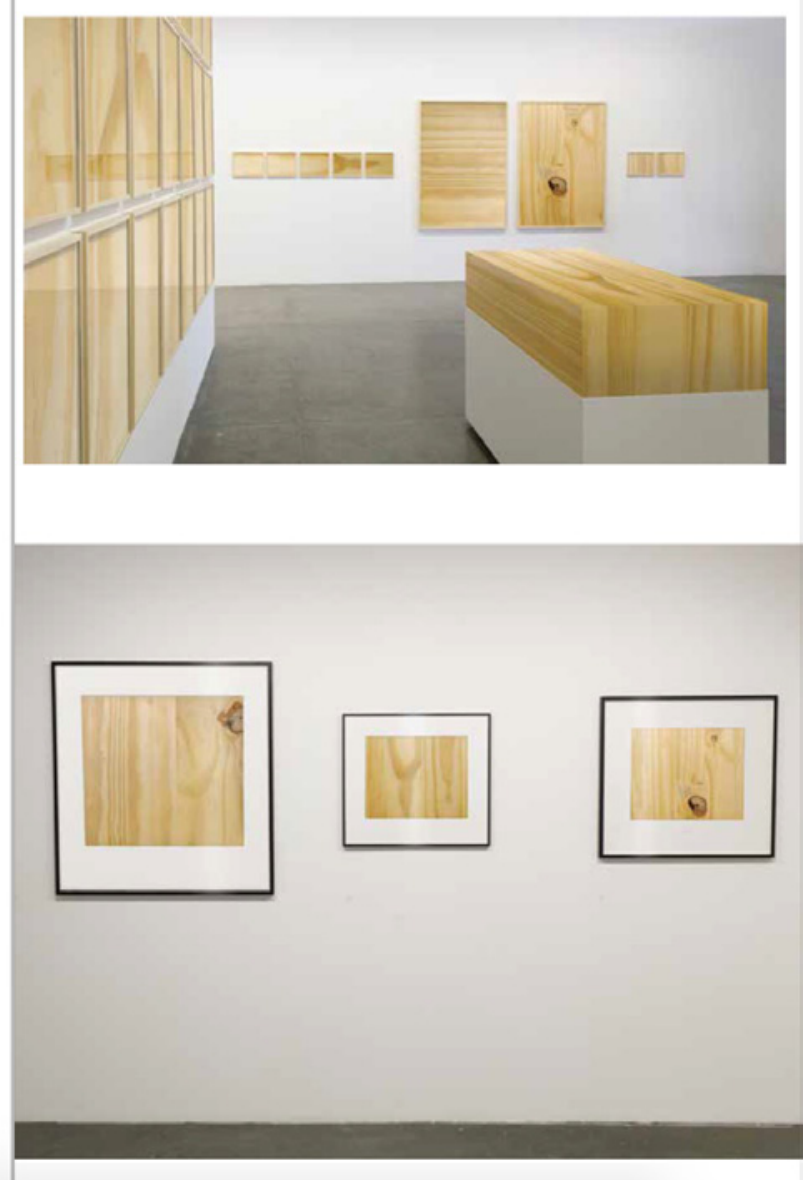

Figura 6. Páginas das artistas Hamona \& Hillary em Art Book 
sexuais diversas recebe o título de $O$ dia em que fui enrabada numa festa infantil (Fig. 7) e causa constrangimento nas instituições que a exibem. Depnneu relata:

Marie já fabricou moldes em bronze de sua própria vagina e entregou para uma lista VIP dos 100 mais importantes colecionadores do mundo. Também foi ela a artista que reservou em latas de sopa Campbell's durante um ano sua menstruação e chamou a série de Meu legítimo trabalho de pop art. A regra é clara: quanto mais absurdo e chocante for a ideia, melhor (MORESCHI, p. 178).
É bem verdade que parte considerável das polêmicas relatadas na publicação não são apenas faniquitos egocêntricos de artistas, mas consequências do contexto em que o autor está inserido como sociedades opressoras que o obrigam a enfrentar o sistema político e econômico vigente para denunciar problemas diversos, em especial a impossibilidade da livre expressão das pessoas que ali vivem. Nas biografias de Rachel Gordon e Andrew Lange, respectivamente, Malala Rejala "não teme em afirmar recorrentemente que seus trabalhos são resultados diretos de

\section{Marie Thompson}

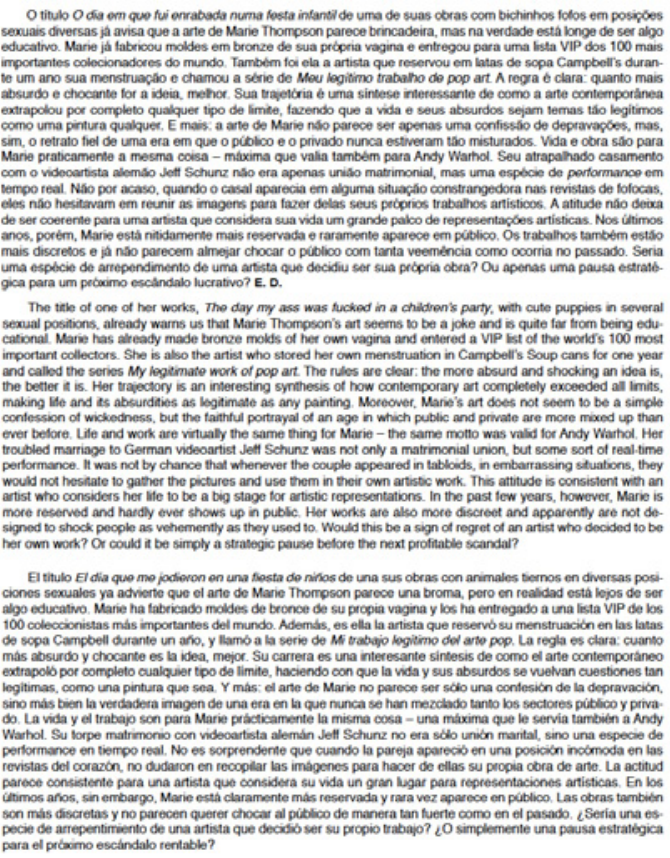

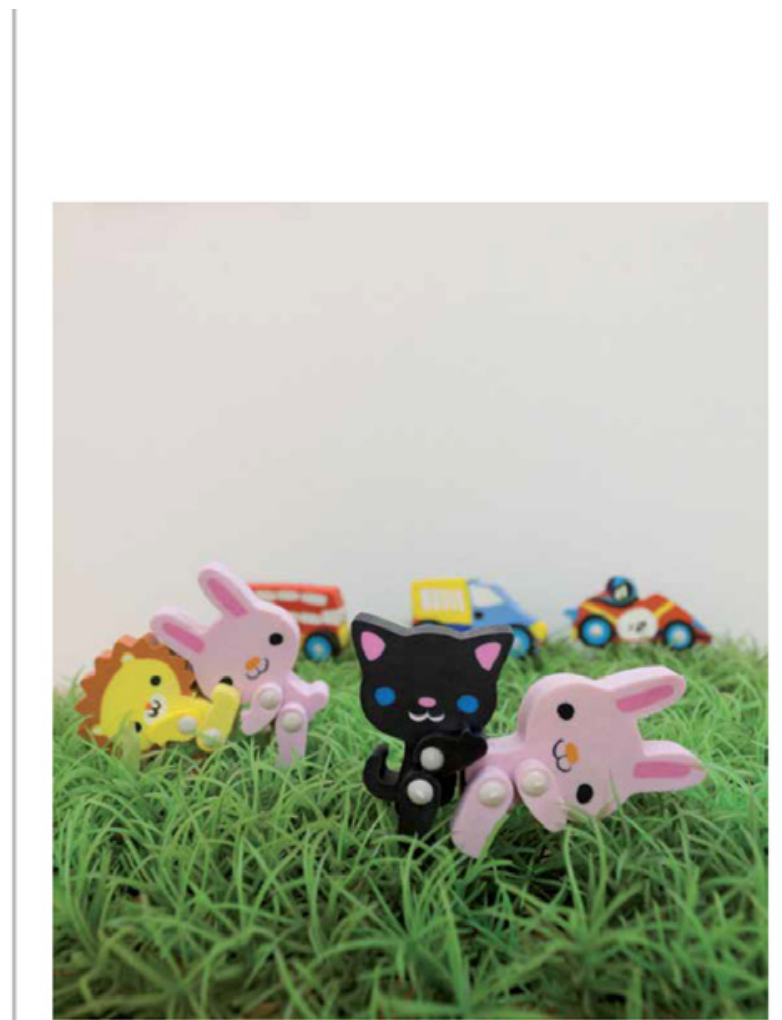

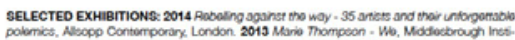

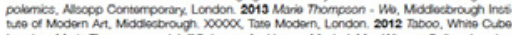

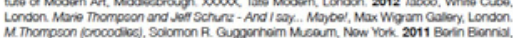

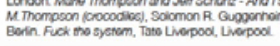

Figura 7. Página da artista Marie Thompson em Art Book. 
sua condição no mundo - uma mulher no Irã" (MORESCHI, p. 130) e George Sandes "nunca foi um crítico ferrenho do governo de Fidel Castro até o ano de 1992, quando projetou nos céus de Havana um feixe luminoso que reproduzia diversos símbolos de governos totalitaristas como a suástica nazista" (MORESCHI, p. 142). Já Abdul-Rafi Fayad, que é representado em Art Book nu e sempre com expressão de raiva (Fig. 8), vocaliza o protesto daqueles artistas que tiverem seus países invadidos por potências estrangeiras:

... carrega consigo a dor de ter visto morrer em seus braços dois de seus irmãos mais velhos na Guerra do
Golfo enquanto trabalhavam como voluntários em Falluja, uma das cidades mais atingidas nas duas invasões norte-americanas" (MORESCHI, p. 18).

É nessa categoria de protesto que parte das mulheres artistas de Art Book parece se enquadrar. Elas almejam, com suas obras, discutir "as feridas raciais ainda tão presentes na sociedade dos Estados Unidos" (MORESCHI, p. 62) como conta Gllen Powel na biografia da artista negra Macy Hudson; ou, tal qual a biografia da espanhola Núria Moyano, escrita por Gllen Powel, fazer o público ficar cara a cara com o assédio moral e sexual sofrido pelas
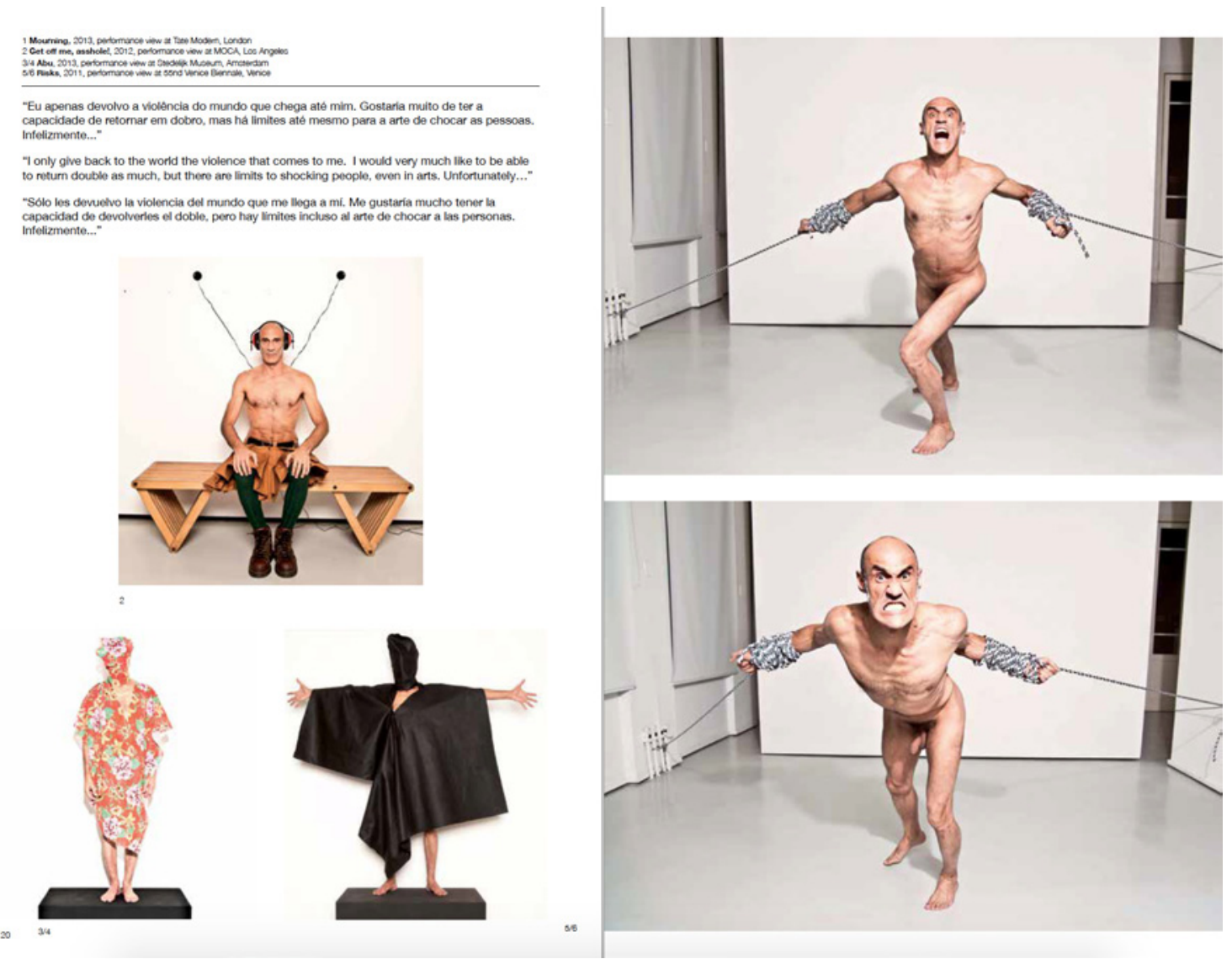

Figura 8. Página do artista Abdul-Rafi Fayad em Art Book. 
mulheres, obra exibida em um apertado corredor na Bienal de Veneza de 2011:

Entrar ali era se espreitar em duas paredes e caminhar com dificuldade até o outro lado. A posição incômoda obrigava o visitante a ficar cara a cara com uma série de 100 fotografias de pelos pubianos de diferentes mulheres que trabalhavam em um mesmo escritório de contabilidade de Nova York, famoso por denúncias de assédio moral e sexual contra inúmeras funcionárias que ali trabalhavam (MORESCHI, p.98).

Curioso notar que as artistas de Art Book situam-se em extremos: ou são combativas e falam da condição de ser mulher em um mundo machista como as duas artistas acima, ou são descritas como autoras de obras esteticamente agradáveis como os vídeos com formas abstratas exibidos em espaços públicos da estadunidense Marie Parker e as pinturas da brasileira Paula Sampaio que, segundo Ed Depnneu, "carrega um otimismo que parece nos lembrar de como a arte pode ser uma ferramenta apropriada para encantar pessoas dos mais diversos tipos" (MORESCHI, p. 138).

Ainda de acordo com o estudo das biografias de Art Book a partir de seus blocos temáticos, dois dos mais comuns temas de trabalhos artísticos descritos na publicação parecem ser a natureza (Elizabeth Depner, na biografia de Andrew Lange, por exemplo, já transportou uma conífera de 12 metros de altura da China para os Estados Unidos para relativizar as noções de fronteiras geográficas) e o corpo humano como é bem notado por Robert Epson nos primeiros trabalhos de Bob Jarry: mosaicos de fotografias de detalhes de um mesmo corpo organizados aleatoriamente e que produzem novos tipos de anatomias humanas.
Em relação às técnicas descritas nas biografias, o campo parece ser o mais ampliado possível, mas os textos sobre pintores, mesmo sendo autores de pinturas bastante diferentes entre si, parecem se preocupar com um certo conjunto de argumentos que defendem a ainda pertinência dessa tradição na arte contemporânea. Defender a pintura como tal seria uma necessidade do mercado diante da ampliação de suportes e técnicas na arte contemporânea? Art Book parece indicar que sim. Na visão de Gllen Powel, o alemão Adolf Flynt não pode ser caracterizado apenas como um pintor de formas geométricas simples como vimos nas fotografias de suas obras, mas uma espécie de criador conceitual que "pinta o próprio ato de se pintar" na tentativa de "entender se há ainda algum sentido em perpetuar essa técnica já tão consagrada na História da Arte" (MORESCHI, p. 22). Por ano, Paul Miller costuma apresentar ao público no máximo 10 telas com gotejamento de tinta azul. Também anualmente, duas pinturas de Edgar Kessler costumam ficar prontas.

Esse ponto, a defesa da pintura como arte ainda pertinente, pode ser visto a princípio como um momento raro de Art Book: aquele que em ele se coloca finalmente crítico ao sistema de arte que tem como tema. As biografias dos pintores indicam certa preferência pela técnica uma crítica explícita aos outros tipos mais ampliados de arte?

A suspeita não parece se confirmar em um segundo olhar. Em ao menos duas das biografias desses artistas, a defesa pela pintura é evidentemente não um apreço por esse tipo de arte, mas uma defesa de um tipo de objeto artístico dos mais valorizados no mercado de arte. Mais uma vez, como sempre em suas páginas, Art 
Book está a serviço do sistema em que se insere, o mercado de arte: "Parece evidente que sua restrição [as poucas pinturas feitas por ano de Edgar Kessler] está intimamente ligada a uma estratégia de valorizar suas telas no mercado de arte internacional" (MORESCHI, p. 74) e:

Com a pequena quantidade de obras [de Paul Miller], os preços sobem. Em 2013, uma tela de apenas 7 centímetros do artista foi leiloada por 62 milhões de dólares na Sotheby's e comprada por um colecionador russo anônimo que não permite sua reprodução e exibição (MORESCHI, p. 90).

\section{Os artistas}

O terceiro conjunto de vozes de Art Book é o dos 50 tipos de artistas ali apresentados. Aqui existe um paradoxo que não parece exclusivo dessa enciclopédia, mas presente em grande parte dos livros que são compêndios de artistas. Apesar de Art Book ter como material central informações acerca de 50 supostos artistas, ali pouco se encontra suas próprias considerações sobre as pesquisas e obras que realizaram. No livro em questão, mas também em Art Now e outras publicações do gênero, esses artistas se expressam apenas em frases curtas que aparecem nas páginas como anúncios, uma quantidade de textos irrisória se comparada àquelas assinados pelos biógrafos ou pelos especialistas convidados a escreverem no final do livro. As declarações são afirmações superficiais, de caráter publicitário, sem indicação da época e situação em que foram ditas, tampouco se passaram por algum tipo de edição (Fig. 9).

"Já me perguntaram se o que eu faço é arte. Eu respondi que não. É só um conjunto de porcarias que preenche a lista de excentricidades de pessoas muito, muito ricas."

"I have been asked if what I do is art. I said it is not. It is only a bunch of crap that meets the eccentricities of very, very rich people."

"Ya me han preguntado si lo que hago es arte. Les dije que no. Es una colección de basura que llena la lista de excentricidades de los muy, muy ricos."

Figura 9. Páginas de Art Book mostrando uma das declarações dos artistas. 
Em geral, as aspas estão ali somente para defender ideias formuladas nos textos dos biógrafos sobre o artista e ajudar no processo de reduzi-los a estereótipos facilmente reconhecíveis por quem conhece um pouco de arte contemporânea. Artistas descritos como polêmicos, por exemplo, mantêm o tom combativo de suas notas biográficas ao se pronunciarem no livro. É o que faz Ed Wortmann ao declarar que "não há nada mais irritante que o conformismo" (MORESCHI, p. 202) e Marie Thompson, com sinceridade desconcertante: "Já me perguntaram se o que eu faço é arte. Eu respondi que não. É só um conjunto de porcarias que preenche a lista de excentricidades de pessoas muito, muito ricas" (MORESCHI, p. 178).

Outras declarações reforçam o laconismo da arte, como já analisamos em algumas das biografias do livro. É o caso de Edmund Harry que lança a enigmática equação "Identificação + reconstrução = utopia real" (MORESCHI, p.50), e Steve Peterson que faz aquilo que diz que não irá fazer: "O que tenho a declarar é que nada tenho a declarar" (MORESCHI, p.118). Arthur Orthof ao afirmar que "a verdade só existe para ser totalmente questionada" (MORESCHI, p.110) nos avisa do caráter de paródia do livro. Mas tão logo o aviso se dissipa com outras frases de efeito como a de Razvan Ionut: "O artista é um intelectual público" (MORESCHI, p.66).

Outros artistas reiteram certo heroísmo romântico como faz Roberto Girotto ao afirmar que não tem medo de pintar, de ser artista, de errar e de quase nada. Aliás, os pintores se pronunciam no livro como enfants terribles e, assim como suas biografias, defendem com afinco a pertinência da pintura. Adolf Flynt resume suas atividades artísticas: "Pensar, rebelar e pintar" (MORESCHI, p. 22). E Clarice Stone oferece uma analogia entre pintura e compreensão de mundo: "Pinto o que é impossível de se traduzir em palavras" (MORESCHI, p. 174).

Duas declarações artísticas valem ser destacadas aqui por razões diferentes. A primeira, de Mathias Nunes, por sintetizar de forma bem-humorada o funcionamento da relação artista e público iniciado nas artes visuais: "Vamos combinar o seguinte: eu faço arte, e vocês dizem que ela é incrível" (MORESCHI, p. 106). A segunda, de Keith Walker, pela estranheza, pois defende a própria ação do livro que reduz a participação dele e dos outros artistas: "Em vez de ouvir um artista, não seria melhor olhar seus trabalhos?" (MORESCHI, p. 194).

Art Book não informa o contexto original em que Walker lançou essa pergunta.

\section{Os convidados}

Críticos de arte, historiadores, curadores e jornalistas especializados em artes visuais foram convidados para escrever nas páginas finais de Art Book. Trata-se de uma seção do livro com papel de tipo e gramatura diferentes do restante da publicação, pois ali parece ser um espaço aparentemente independente do livro como informa um aviso inicial na primeira dessas páginas: "Esses pensadores tiveram total liberdade para expressar suas opiniões (positivas ou negativas) sobre a publicação" (MORESCHI, p. 211).

Espanta saber que um projeto que já em seu prefácio arma-se para evitar as críticas sobre sua estrutura frágil abra um espaço final de tamanho considerável (40 páginas de um total de 250) para pessoas que não participaram do projeto e, 
por isso, aptas a não só elogiarem seu conteúdo, mas também apontar problemas.

As críticas não são poucas. Em seu texto para a seção final, a curadora paulista Ananda Carvalho relata sua participação em um seminário de 2013 que, segundo a autora, ocorreu no Node Center for Curatorial Studies, em Berlim. Buscou-se registros sobre esse evento para a escrita deste artigo, mas nada foi encontrado na internet e tampouco nos arquivos da instituição alemã. Para Ananda Carvalho, finalizado o seminário, uma fragilidade permaneceu:

(...) questionei o critério de escolhas dos artistas da enciclopédia ART BOOK. Afirmei que, até o momento, não conseguia entender por que a escolha desses artistas e não de outros. A situação gerou um nítido desconforto na plateia, em especial na primeira fileira do auditório, onde se localizava parte da equipe que produziu a ART BOOK. Não me importei e minha dúvida persiste (MORESCHI, p. 225).

O historiador alemão Joseph Imorde é autor do texto que aponta problemas graves nas abordagens enciclopédicas sobre a arte contemporânea como as feitas em Art Book. Segundo ele, esse mal de tentar incorporar a "história inteira", abordar nada menos do que o "arquivo global" perpassa as publicações de arte e são também percebidos em mostras como a Bienal de Veneza de 2013 que, a seu ver, tentou "preencher imensos espaços de exibição com materiais dos mais heterogêneos para expor teorias sobre tudo" (MORESCHI, p. 216).

Ainda de acordo com Imorde, a razão para que artistas aceitem essa preferência enciclopédica e superficial de apresentar a arte pode ser explicada pela citação que abre seu artigo e é assinada como sendo de Walter Benjamin: "Ter uma entrada em uma enciclopédia é como ter um monumento em frente a um teatro de ópera" (MORESCHI, p. 216). E mais:

Tais esforços enciclopédicos podem ser entendidos como uma iniciativa compensatória para um entendimento sobre o mundo demasiadamente complexo no qual vivemos, uma distração da realidade com a qual a maioria já perdeu contato. Aqueles que estão fadigados com as exigências excessivas da nossa sociedade de capitalismo tardio ou aqueles que se sentem extenuados pelas exigências da nossa era digital podem encontrar refúgio nas simplificações exageradas que as enciclopédias visuais oferecem - ordem, redução e abrangência (MORESCHI, p. 216).

Apesar de menos crítico a esse tipo de publicação e curadoria, o professor do Instituto de Artes da Unicamp, Paulo Kühl, não deixa de destacar deficiências na proposta editorial de Art Book em seu texto, em especial ao destacar artistas aparentemente polêmicos, mas facilmente aceitos pelo sistema da arte vigente:

A contestação, que parece ser uma marca dessa produção [ele fala aqui do próprio livro], é ao mesmo tempo impulsionada pelas instituições, o que às vezes se mostra como contraditório. De um lado, vemos com certo prazer o exercício constante de uma atitude crítica; de outro, surge um incômodo ao percebermos que esse impulso crítico se consolida numa aceitação que parece ser generalizada, perdendo assim parte de sua força (MORESCHI, p. 219).

O curador paulistano Paulo Miyada é o único dos nove autores que parece não concordar com críticas ao modo 
enciclopédico tal qual visto em Art Book. Isso, porém, não significa que ele não vê problemas na publicação. Seu pensamento é dos mais sofisticados e acredita que os problemas são outros. Para ele, não são os estereótipos apresentados em Art Book ou em qualquer outro livro ou exposição que criam a produção artística atual. As leituras padronizadas da arte são apenas consequências de um sistema da arte contemporâneo que se preocupa de fato não com as tipologias, mas com os processos criativos. Como justificativa, ele afirma:

Colocando de forma resumida, o filósofo Arthur Danto define a arte contemporânea como a atividade capaz de refletir dialeticamente sobre seus próprios meios e, também, de criticar as cadeias de produção de sentido do pensamento humano. Se quisermos acreditar nisso, resumir a produção dos artistas aos estereótipos aplicados sobre ela implica em perder o foco do que mais importa. Ao compreender simplesmente as alegorias que vestem os artistas, esquecemo-nos dos movimentos críticos que suas obras podem alavancar (MORESCHI, p. 213).

Mas não são só as críticas e as ressalvas ao livro que caracterizam esses textos. Em comum, todos terminam com uma espécie de aviso aos leitores - aviso esse indireto, inconclusivo, apenas a sugestão de que algo pode ser descoberto na enciclopédia, a saber sua ficcionalidade. Myada termina: "Onde houver um buraco, atenção, pode existir um tesouro" (MORESCHI, p. 213). E Imorde destaca que uma leitura atenta de Art Book: “... pode abrir caminhos para o entendimento de algo desconcertante - a verdade inegável de que todas as visões do mundo são ideologicamente fabricadas" (MORESCHI, p. 217).
Os avisos seguem com Kühl: "Podemos contar, isso sim, com a oportunidade de exercer nossa faculdade crítica, com muito esforço e, tomando atentamente o caminho sugerido por Bruno Moreschi, indagar sobre aquilo que temos diante de nós" (MORESCHI, p.220). E, com mais intensidade, em seu texto, a curadora Paula Borghi destaca até mesmo certa má fé no projeto:

\begin{abstract}
... entendo ART BOOK como um meio perverso para alcançar não só os 15 minutos de fama, como também um canal para escrever o nome do autor/ editor na História da Arte. O que me leva a concluir que Moreschi é um criador/editor surpreendente, perverso e que certamente será um sucesso. (MORESCHI, p. 228)
\end{abstract}

Esses e outros términos de textos na seção final indicam não só o fato de que há algo a ser notado em Art Book, como também transferem a responsabilidade da descoberta para alguém que não os autores desses artigos. Assim como Moreschi editor se utiliza do sistema da arte e da enciclopédia como álibi das consequências aferidas de suas escolhas, esses autores também parecem fazer o mesmo, agora passando a conta para quem lê.

\section{O Leitor}

Assim, surge a voz que me parece mais fundamental para Art Book, aquela extrapágina, que se situa além dos autores e assinaturas do projeto: o leitor. Depende dele e só dele a escolha de tornar Art Book uma enciclopédia de fato relevante para melhor compreender grandes artistas e obras; e/ou defini-la como um estudo experimental sobre os padrões encontrados 
em livros de arte, discutindo também como essas publicações atuam como espaços de legitimação de sujeitos e modos nas artes visuais.

É por isso que o leitor parece-me de fato a grande voz do projeto, para tristeza de Bruno Moreschi editor que nem sempre consegue controlar a ação de quem lê, tal qual faz com as vozes dos biógrafos, dos artistas e de certa maneira dos autores dos textos finais - ao conseguir fazer com que eles apenas sugiram e não revelem por completo a ficcionalidade do projeto.

É o leitor quem pode perceber, decidir e julgar. E sua atuação em Art Book (e talvez em todos os outros livros de arte) lembra o multifacetado livro Fogo Pálido, escrito em 1962 por Vladimir Nabokov. Ali, na introdução escrita por Charles Kinbote, um narrador pouco confiável, amigo e vizinho do autor dos poemas que serão mostrados no livro, há um aviso que provavelmente soaria ameaçador para Bruno Moreschi e sua equipe, assim como para todos os outros editores, artistas e curadores: "Provavelmente meu querido poeta não teria subscrito tal afirmação, mas, para o bem ou para o mal, é o comentador que tem a última palavra" (NABOKOV, 2004, p. 21).

\section{Referências}

ARGAN, Giulio C. Arte Moderna. São Paulo: Cosac Naify, 1992.

BAKHTIN, Mikhail. Teoria do Romance I. A Estilística. São Paulo: Editora 34, 2015.

BAKHTIN, Mikhail. Os Gêneros do Discurso. São Paulo: Editora 34, 2015.

MORESCHI, Bruno (Ed.). Art Book. São Paulo: Menard Editions, 2014.

NABOKOV, Vladimir. Fogo Pálido. São Paulo: Círculo do Livro, 1990.

Recebido: 1 de junho de 2017. Aceite: 12 de setembro de 2017 . 